\title{
A comparison of the accuracy of an adjusted fuzzy time series forecasting method with the traditional method application to Thailand rubber price
}

\author{
Kanittha Yimnak ${ }^{*}$ \\ Department of Mathematics and Statistics, Dhurakij Pundit University, Thailand
}

\author{
Index Terms \\ Fuzzy Time Series \\ Thailand Rubber Price \\ Symmetric Trapezoidal Fuzzy \\ Numbers \\ Traditional Method \\ Uncertain Data.
}

Received: 9 April 2015

Accepted: 25 July 2015

Published: 22 February 2016

\section{INTRODUCTION}

The accuracy of forecasting techniques isessential, especially economy and social data, because it leads toset the policy of developing country. The mostly time series data are uncertain data. The accuracy of interpretation of uncertain data is interest. Normally, The traditional time series forecasting methods such as moving average, smoothing exponential, Box-Jenkins and the other classical methods are well-known for time series. However, these methodsdo not satisfy for forecasting problem in which the time series data are linguistic values. In addition, for uncertain time series data, there will be less accurate when using these methods. Fuzzy time series forecasting method is a good alternative for uncertain data. It has been widely

\footnotetext{
*Corresponding author: Kanittha Yimnak

E-mail: kanittha.yim@dpu.ac.th
}

such as forecasting the weather, earthquakes, stock fluctuations and any phenomenon indexed by variables that change unpredictably in time. The nearest trapezoidal approximation is proposed by [1]. This approximation operator preserving expected interval and possesses many desired properties. In some situations their operator many fail to lead a trapezoidal fuzzy number. In 2007 [2], suggested the efficient process of trapezoidal approximation operator. [3] found that the nearest symmetric trapezoidal fuzzy numbers enhanced the forecasting accuracy for fuzzy time series forecasting method. The accuracy of forecasting time series data in this process increases. In this research, the price of raw rubber of Thailand is used for numerical experiment. The accuracy of the presented method and the traditional method are compared by the Mean Absolute Percentage Error (MAPE). 


\section{TRADITIONAL METHODS}

There are many traditional forecasting methods,i.e., the simple linear regression model satisfying the time series that components of trend, Box-Jenkins method satisfying a stationary time series that feature finite order Moving Average (MA(q)), finite order Autoregressive (AR(p)) model, mixture of finite order Autoregressive And Moving Average $\operatorname{ARMA}(\mathrm{p}, \mathrm{q})$ and $\operatorname{ARIMA}(\mathrm{p}, \mathrm{d}, \mathrm{q})$ model for nonstationary data using ARMA models defined on the $d^{\text {th }}$ difference of the original process and the time series data comprising influenced by the seasonality-periodic or $\operatorname{SARIMA}(\mathrm{p}, \mathrm{d}, \mathrm{q})(\mathrm{P}, \mathrm{D}, \mathrm{Q})_{\mathrm{s}}$ model that repeat with about the same intensity each year.

The AR(p) model is the $p^{\text {th }}$ order autoregressive time series and $X_{k}$ can be solved by the following equation[4].

$$
\sum_{i=0}^{p} \rho_{i} X_{k-i}=\varepsilon_{k}, \quad k=0, \pm 1, \pm 2, \ldots
$$

where $\rho_{0} \neq 0, \rho_{\mathrm{p}} \neq 0$ and the $\varepsilon_{\mathrm{k}}$ are typically assumed to be uncorrelated $\left(0, \sigma^{2}\right)$ random variables (i.e.E[ $\left[\varepsilon_{0}\right]=$ $0, \mathrm{E}\left[\varepsilon_{0}^{2}\right]=\sigma^{2}$ ). Thus, the $\operatorname{AR}(1)$ process is a first order autoregressive time series and most commonly defined by the following equations

$$
\mathrm{X}_{\mathrm{k}}=\rho \mathrm{X}_{\mathrm{k}-1}+\varepsilon_{\mathrm{k}}, \quad \mathrm{k}=0, \pm 1, \pm 2, \ldots
$$

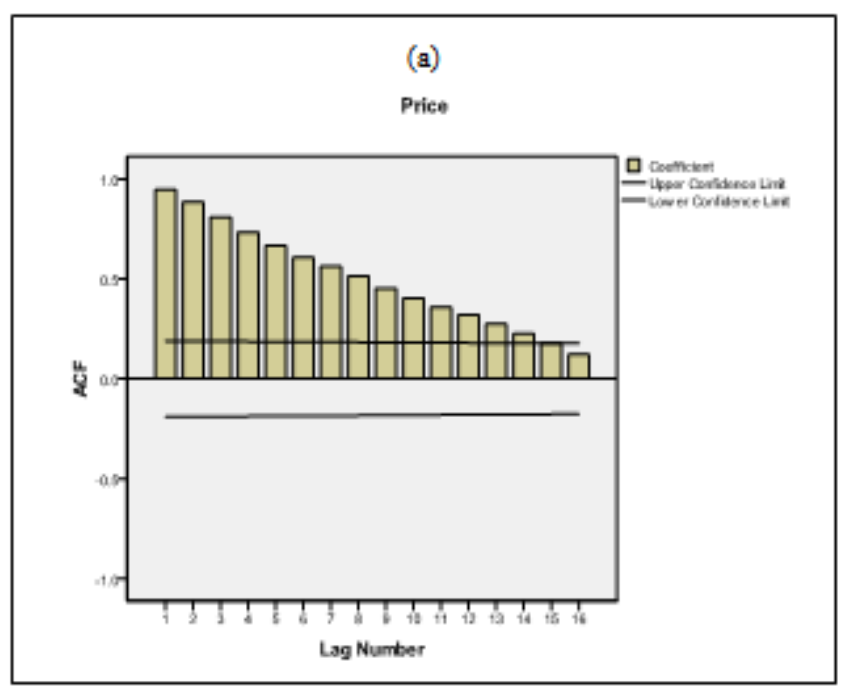

which is simply a first order linear difference equation. Note that $X_{k}$ is represented as alinear function of $X_{k-1}$ and $\varepsilon_{k}$ It can also be shown that for this model [5].

1. The Theoretical Autocorrelation Function (TACF) dies down (that is, the values $r_{1}, r_{2}, \ldots$ decrease in a steady fashion). For the working series $X_{b}, X_{b+1}, \ldots, X_{n}$ : the simple autocorrelation at lag $k$ is

$$
r_{k}=\frac{\sum_{t=b}^{n-k}\left(X_{t}-\bar{X}\right)\left(X_{t+k}-\bar{X}\right)}{\sum_{t=b}^{n}\left(X_{t}-\bar{X}\right)^{2}},
$$

where

$$
\bar{X}=\frac{\sum_{t=b}^{n} X_{t}}{n-b+1}
$$

2. The Theoretical Partial Autocorrelation Function (TPACF) has a nonzero partial autocorrelations at lag 1 and has zero partial autocorrelations at all lags after lag1 (that is, cuts off after lag 1). Said equivalently, $r_{k k} \neq 0$ for $\mathrm{k}=1, \mathrm{r}_{\mathrm{kk}}=0$ fork $>1$,

$$
r_{k k}=\left\{\begin{array}{cl}
r_{1} & ; k=1 \\
\frac{r_{k}-\sum_{j=1}^{k-1} r_{k-1, j} r_{k-j}}{1-\sum_{j=1}^{k-1} r_{k-1, j} r_{j}} & ; k=2,3, \ldots
\end{array}\right. \text { ， }
$$

wherer $\mathrm{kj}_{\mathrm{j}}=\mathrm{r}_{\mathrm{k}-1, \mathrm{j}}-\mathrm{r}_{\mathrm{kk}} \mathrm{r}_{\mathrm{k}-1, \mathrm{k}-\mathrm{j}}$ for $\mathrm{j}=1,2, \ldots, \mathrm{k}-1$

The TACF and TPACF of the numerical experiment show in figure 1.

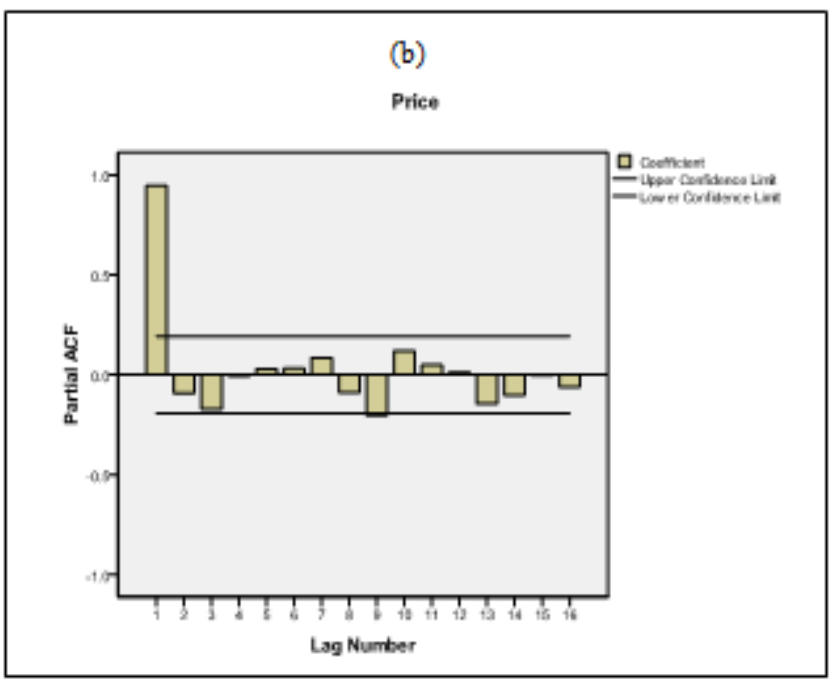

Fig. 1. The TACF and TPACF of Thailand rubber price; (a) TACF: (b) TPACF

In this study, the AR(1) model corresponding to Thailand rubber price data is chosen for comparison to an adjusted fuzzy time series forecasting method. For the AR(1) model, the $\varepsilon_{k}^{\prime} s$ are considered as a random 
variables. Moreover, they areoften mentioned in the error terms or innovations. For the difference equation (2), $\mathrm{X}_{\mathrm{k}}$ can be solved byknowing the value of $\mathrm{X}_{\mathrm{k}-1}$, and $\mathrm{X}_{\mathrm{k}-1}$ is gained from knowing $\mathrm{X}_{\mathrm{k}-2}$ and so on, $\mathrm{X}_{0}$ is an initial value that is k-time periods prior.

$$
\begin{aligned}
X_{k} & =\rho X_{k-1}+\varepsilon_{k} \\
& =\rho\left(\rho X_{k-2}+\varepsilon_{k-1}\right)+\varepsilon_{k} \\
& =\rho^{2} X_{k-2}+\rho \varepsilon_{k-1}+\varepsilon_{k} \\
& =\rho^{3} X_{k-3}+\rho^{2} \varepsilon_{k-2}+\rho \varepsilon_{k-1}+\varepsilon_{k} \\
& \vdots \\
= & \rho^{N} X_{k-N}+\rho^{N-1} \varepsilon_{k-(N-1)}+\ldots+\rho \varepsilon_{k-1}+\varepsilon_{k}
\end{aligned}
$$

Thus, for every $\mathrm{N}$

$$
X_{k}=\rho^{N} X_{k-N}+\sum_{i=0}^{N-1} \rho^{i} \varepsilon_{k-i}
$$

The limit as $\mathrm{N} \rightarrow \infty$ of equation (6) and for $|\rho|<1$ indicates $\mathrm{X}_{\mathrm{k}}=\sum_{\mathrm{i}=0}^{\infty} \rho^{\mathrm{i}} \varepsilon_{\mathrm{k}-\mathrm{i}}$ must be the solution of the difference equation, assuming that the infinite sum $\sum_{\mathrm{i}=0}^{\infty} \rho^{\mathrm{i}} \varepsilon_{\mathrm{k}-\mathrm{i}}$ exists. If $\varepsilon_{\mathrm{k}}$ is stationary, then $\sum_{\mathrm{i}=0}^{\infty} \rho^{\mathrm{i}} \varepsilon_{\mathrm{k}-\mathrm{i}}$ is also stationary. The distribution of our error terms are found before finding the distribution of our data. To find the distribution of our data, we need to first find the distribution of our error terms. Therefore, we solve for $\epsilon_{\mathrm{k}}$. Recall,

$$
\begin{aligned}
& X_{k}=\rho X_{k-1}+\epsilon_{k} \\
& \widehat{\epsilon}_{k}=X_{k}-\hat{\rho} X_{k-1}
\end{aligned}
$$

We obtain our least squares estimator for $\rho$ :

$$
\hat{\rho}=\frac{\sum_{\mathrm{k}=2}^{\mathrm{n}} \mathrm{X}_{\mathrm{k}} \mathrm{X}_{\mathrm{k}-1}}{\sum_{\mathrm{k}=2}^{\mathrm{n}} \mathrm{X}_{\mathrm{k}-1}^{2}} \text {. }
$$

By estimating $\hat{\rho}$, we can see the correlation between each observation from time period to time period.

\section{A. The Fuzzy Time Series Forecasting Method Based on the Nearest Symmetric Trapezoidal Fuzzy Numbers}

[3] proposed 8 steps for this modified method.

Step 1: Assemble the fuzzy time series data $A v_{t}$.

Step 2: Determine $D_{\max }$ and $D_{\min }$ are the maximum and the minimum among all $A v_{t}$, respectively. Theuniverse of discourse two small numbers $D_{1}$ and $D_{2}$ are assigned as

$$
\mathrm{U}=\left[\mathrm{D}_{\min }-\mathrm{D}_{1}, \mathrm{D}_{\max }+\mathrm{D}_{2}\right]
$$

Step 3: The universe is divided in to seven equal length intervals $U_{i}, i=1,2, \ldots, 7[6]$ according to the distribution of the historical data. $\mathrm{U}_{\mathrm{i}}$ is divided into intervals of different length and denotes $v_{j}$.

$$
\mathrm{v}_{1}=\left[\mathrm{d}_{1}, \mathrm{~d}_{2}\right], \quad \mathrm{v}_{2}=\left[\mathrm{d}_{2}, \mathrm{~d}_{3}\right], \ldots, \mathrm{v}_{\mathrm{m}}=\left[\mathrm{d}_{\mathrm{m}}, \mathrm{d}_{\mathrm{m}+1}\right]
$$

Step 4: Define trapezoidal fuzzy number. The fuzzy sets which are defined on trapezoidal fuzzy numbers are as follows:

$$
\begin{gathered}
A_{1}=\left[d_{0}, d_{1}, d_{2}, d_{3}\right] \\
A_{2}=\left[d_{1}, d_{2}, d_{3}, d_{4}\right] \\
\vdots \\
A_{m-1}=\left[d_{m-2}, d_{m-1}, d_{m}, d_{m+1}\right] \\
A_{m}=\left[d_{m-1}, d_{m}, d_{m+1}, d_{m+2}\right]
\end{gathered}
$$

Step 5: Classify all the data in to the corresponding fuzzy numbers. The time series data belongs to the fuzzy number $A_{j}$ when the value of time series data is located in the range of $v_{j}$.

Step 6: Defined the fuzzy logical relationship under the condition that if $\operatorname{Av}_{t}(t-1)=A_{i}$ and $A v_{t}(t)=A_{j}$ then $a$ fuzzy logical relationship can be defined as $A_{i} \rightarrow A_{j}$, where $A_{i}$ and $A_{j}$ are called the left hand side and the right hand side of the fuzzy logical relationship respectively $[7,8,9]$.

Step 7: Arrange the fuzzy logical relationships in to the fuzzy logical relationship groups

based on the same fuzzy number on the left hand sides of the fuzzy logical relationships. If the transition happens to the same fuzzy set, make a separate logical relationship group. The fuzzy logical relationship groups are like the following;

$$
A_{j} \rightarrow A_{k 1}, A_{j} \rightarrow A_{k 2}, \ldots, A_{j} \rightarrow A_{k p}
$$

Step 8: Forecast time series data. The forecasted value at time $t, F_{t}$, can be solved by the following three heuristic rules.Suppose the fuzzy number $A v_{t}$ at timet -1 is $A_{j}$.

Note: For the trapezoidal fuzzy number $A=\left(t_{1}, t_{2}, t_{3}, t_{4}\right)$ where $\left[\mathrm{t}_{2}, \mathrm{t}_{3}\right]$ is core of $\mathrm{A}, t_{1}$ is left width and $t_{4}$ is right width, then the nearest symmetric trapezoidal fuzzy number for $\mathrm{A}$ is:

$$
\left(t_{2}+\frac{t_{4}-t_{1}}{4}, t_{3}+\frac{t_{4}-t_{1}}{4}, \frac{t_{1}+t_{4}}{2}\right)[7,8,9]
$$

Rule 1: If the fuzzy logical relationship group of $A_{j}$ is empty, $A_{j} \rightarrow \varphi$ or $\mathrm{A}_{\mathrm{j}} \rightarrow \mathrm{A}_{\mathrm{j}}$, then the forecasted valueFv $\mathrm{v}_{\mathrm{t}}$ is $\mathrm{R}\left[\operatorname{NSTFN}\left(\mathrm{A}_{\mathrm{j}}\right)\right]$

Note: A ranking function is a map from the set of fuzzy numbers $F(R)$ into areal line and is defined by

$$
R(A)=\frac{a+b+c+d}{4}, \quad A=(a, b, c, d)
$$


Rule 2: If the fuzzy logical relationship group of $A_{j}$ is one to one, i.e., $A_{j} \rightarrow A_{k}$ then the forecasted value $F_{t}$ is $\mathrm{R}\left[\operatorname{NSTFN}\left(\mathrm{A}_{\mathrm{k}}\right)\right]$.

Rule 3: If the fuzzy logical relationship group of $A_{j}$ is one to many, i.e.,

$A_{j} \rightarrow A_{k 1}, A_{j} \rightarrow A_{k 2}, \ldots, A_{j} \rightarrow A_{k p}$ then the value of $F v_{t}$ is calculated as:

$$
\mathrm{Fv}_{\mathrm{t}}=\mathrm{R}\left[\frac{\operatorname{NSTFN}\left(A_{\mathrm{k} 1}\right)+\operatorname{NSTFN}\left(A_{k 2}\right)+\ldots+\operatorname{NSTFN}\left(A_{\mathrm{kp}}\right)}{\mathrm{p}}\right]
$$

\section{B. Numerical Example}

This section presents the steps for forecasting the prices of raw rubber in Thailand. The Mean Absolute Percentage Error (MAPE) is used to evaluate the forecasting. The formula is:

$$
\text { MAPE }=\frac{1}{n} \sum_{\mathrm{t}=1}^{\mathrm{n}}\left|\frac{A v_{\mathrm{t}}-\mathrm{Fv}_{\mathrm{t}}}{A \mathrm{v}_{\mathrm{t}}}\right| \times 100
$$

Step 1: The rubber prices are collected from January2007 to December 2015 [10] as shown in table 2.

Step 2: The maximum and minimum data of the rubber price are 172.62 and 34.51 respectively. Let $\mathrm{D}_{1}=1.51, \mathrm{D}_{2}=0.38$. ThenU $=[33,173]$

Step 3: Divide $U$ into seven interval $\mathrm{U}_{\mathrm{i}}, \mathrm{i}=1,2, \ldots, 7$ which equal length of 140 i.e.

$$
\mathrm{U}_{1}=[33,53], \mathrm{U}_{2}=[53,73], \ldots, \mathrm{U}_{7}=[153,173]
$$

TABLE 1

THE FREQUENCY DISTRIBUTION OF $U_{1}$ TO U $U_{7}$ ARE AS THE FOLLOWING

$\begin{array}{llllllll}\text { Interval } & \mathrm{U}_{1} & \mathrm{U}_{2} & \mathrm{U}_{3} & \mathrm{U}_{4} & \mathrm{U}_{5} & \mathrm{U}_{6} & \mathrm{U}_{7}\end{array}$

No of

historical

$\begin{array}{llllllll}\text { the rubber } & 24 & 26 & 30 & 17 & 5 & 4 & 2\end{array}$

price

Divide the intervals $\mathrm{U}_{\mathrm{i}}, \mathrm{i}=1,2, \ldots, 7$ as follows:

$\mathrm{v}_{1}=[33,33.8), \ldots, \mathrm{v}_{24}=[52.1,53)$ with length 0.8 and 0.9

alternatively.

$\mathrm{v}_{25}=[53,53.7), \ldots, \mathrm{v}_{50}=[72.2,73)$ with length 0.7 and 0.8

alternatively.

$\mathrm{v}_{51}=[73,73.6), \ldots, \mathrm{v}_{80}=[92.3,93)$ with length 0.6 and 0.7

alternatively. $\mathrm{v}_{81}=[93,94.1), \ldots, \mathrm{v}_{97}=[111.8,113)$ with length 1.1 and

1.2 alternatively.

$\mathrm{v}_{98}=[113,117), \ldots, \mathrm{v}_{102}=[129,133)$ with length of 4 .

$v_{103}=[133,138), \ldots, v_{106}=[148,153)$ with length of 5 .

$v_{107}=[153,163), v_{108}=[163,173)$ with length of 10 .

Step4: The fuzzy trapezoidal numbers can be then defined by

$A_{1}=\left[\begin{array}{llll}32.2 & 33 & 33.8 & 34.6\end{array}\right]$

$A_{2}=\left[\begin{array}{llll}33 & 33.8 & 34.6 & 35.4\end{array}\right]$

:

$A_{107}=\left[\begin{array}{llll}148 & 153 & 163 & 173\end{array}\right]$

$A_{108}=\left[\begin{array}{llll}153 & 163 & 173 & 183\end{array}\right]$

Step5: Fuzzify the rubber prices as shown in table2.

Step6: According to the fuzzified the rubber prices, the fuzzy logical relationships are derived as follows:

TABLE 2

FUZZY LOGICAL RELATIONSHIP

\begin{tabular}{llllll}
\hline \hline$A_{41}$ & $A_{51}$ & $A_{47}$ & $A_{51}$ & $A_{53}$ & $A_{47}$ \\
$\rightarrow A_{51}$ & $\rightarrow A_{47}$ & $\rightarrow A_{51}$ & $\rightarrow A_{53}$ & $\rightarrow A_{47}$ & $\rightarrow A_{37}$ \\
$A_{37}$ & $A_{40}$ & $A_{42}$ & $A_{49}$ & & $A_{5}$ \\
$\rightarrow A_{40}$ & $\rightarrow A_{42}$ & $\rightarrow A_{49}$ & $\rightarrow A_{56}$ & $\cdots$ & $\rightarrow A_{5}$ \\
\hline \hline
\end{tabular}

Step 7: Create the fuzzy logical relationship groups as follows:

$\mathrm{A}_{41} \rightarrow \mathrm{A}_{35}, \mathrm{~A}_{46}, \mathrm{~A}_{51}$

$\mathrm{A}_{51} \rightarrow \mathrm{A}_{47}, \mathrm{~A}_{53}$

$\mathrm{A}_{47} \rightarrow \mathrm{A}_{37}, \mathrm{~A}_{49}, \mathrm{~A}_{51}, \mathrm{~A}_{55}$

:

$\mathrm{A}_{15} \rightarrow \mathrm{A}_{15}$

$\mathrm{A}_{98} \rightarrow \mathrm{A}_{102}$

Step8: Calculate the forecasted the rubber prices. For example

[Dec - 10]: The fuzzified enrollment of [Nov. -10] is $A_{98}$ and the corresponding fuzzy logical relationship group

$\mathrm{A}_{98} \rightarrow \mathrm{A}_{102}$

$A_{102}=\left[\begin{array}{llll}125 & 129 & 133 & 138\end{array}\right]$. By note $t_{2}=129 ; t_{3}=133 ;$

$\mathrm{t}_{1}=129-125=4 ; \mathrm{t}_{4}=138-133=5$

$\frac{\mathrm{t}_{4}-\mathrm{t}_{1}}{4}=0.25, \quad \frac{\mathrm{t}_{4}+\mathrm{t}_{1}}{2}=4.5$

$\operatorname{NSTFN}\left(\mathrm{A}_{102}\right)$

$=\left[\begin{array}{llll}129.25-4.5 & 129+0.25 & 133+0.25 & 142.25-4.5\end{array}\right]$

$=\left[\begin{array}{llll}124.75 & 129.25 & 133.25 & 137.75\end{array}\right]$

According to rule3, theFv $\mathrm{v}_{\mathrm{t}}$ for [Dec - 10] is

$\mathrm{Fv}_{\mathrm{t}}=\mathrm{R}\left[\operatorname{NSTFN}\left(\mathrm{A}_{102}\right)\right]=131.250$

[Sep - 08] and[Jun - 08]: the fuzzified rubber prices of

[Sep - 08] and [Jun - 08] is $A_{77}$. The fuzzy logical

relationship group is $A_{77} \rightarrow A_{85}, A_{76}$.

$$
A_{85}=\left[\begin{array}{llll}
96.3 & 97.4 & 98.6 & 99.8
\end{array}\right] . \operatorname{NSTFN}\left(A_{85}\right)
$$


$=\left[\begin{array}{llll}96.275 & 97.425 & 98.625 & 99.775\end{array}\right]$

$$
\mathrm{A}_{76}=\left[\begin{array}{llll}
88.8 & 89.5 & 90.2 & 90.9
\end{array}\right], \operatorname{NSTFN}\left(A_{76}\right)
$$$$
=\left[\begin{array}{llll}
88.8 & 89.5 & 90.2 & 90.9
\end{array}\right]
$$

According to rule3, theFv $v_{t}$ for[Sep - 08] and[Jun - 08] is

$\mathrm{Fv}_{\mathrm{t}}=\mathrm{R}\left[\frac{96.275+88.8}{2}, \frac{97.425+89.5}{2}, \frac{98.625+90.2}{2}, \frac{99.775+90.9}{2}\right]=$ 93.938
For figure 2, the actual data, AR(1) forecasting model and proposed method are coincide. However, the MAPE using proposed method is less than the AR(1) method (see in Table1.). In addition, the MAPE using tradition method is about 2.10 times which compares to the MAPE using proposed method.

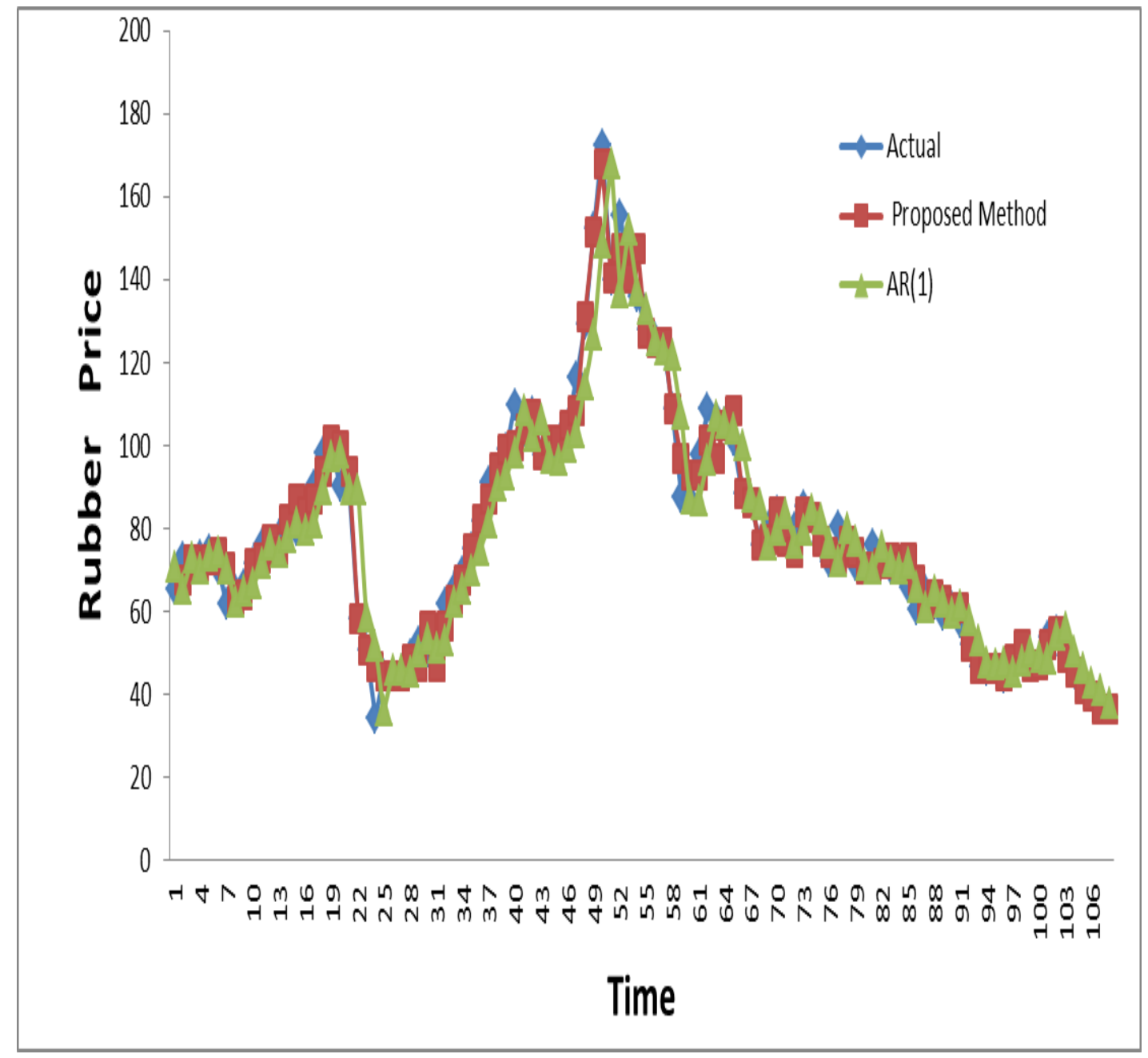

Fig. 2. The actual data the forecasts by AR (1) and the proposed methods.

TABLE 3

A COMPARISON BETWEEN THE MAPE BY THE PROPOSED METHOD AND THE AR(1) METHOD

\begin{tabular}{cccc}
\hline \hline Index & AR (1) & Proposed method & Ratio of AR(1) to proposed method \\
\hline MAPE & 7.551 & 3.597 & $2.10: 1$ \\
\hline
\end{tabular}


TABLE 4

FUZZIFIED AND FORECASTED THE THAILAND RUBBER PRICES

\begin{tabular}{|c|c|c|c|c|c|c|c|c|c|}
\hline Time & $\begin{array}{l}\text { Rubber } \\
\text { Price }\end{array}$ & $\begin{array}{c}\text { Fuzzified } \\
\text { Rubber } \\
\text { Price }\end{array}$ & $\mathrm{Fv}_{\mathrm{t}}$ & MAPE & Time & $\begin{array}{l}\text { Rubber } \\
\text { Price }\end{array}$ & $\begin{array}{c}\text { Fuzzified } \\
\text { Rubber } \\
\text { Price }\end{array}$ & $\mathrm{Fv}_{\mathrm{t}}$ & MAPE \\
\hline Jan-07 & 65.43 & A41 & & & Jul-11 & 127.9 & A101 & 127.000 & 0.0070 \\
\hline Feb-07 & 73.1 & A51 & 67.750 & 0.0732 & Aug-11 & 125.74 & A101 & 125.000 & 0.0059 \\
\hline Mar-07 & 70.19 & A47 & 72.350 & 0.0308 & Sep-11 & 123.96 & A100 & 125.000 & 0.0084 \\
\hline Apr-07 & 73.35 & A51 & 70.738 & 0.0356 & Oct-11 & 109.16 & A94 & 108.800 & 0.0033 \\
\hline May-07 & 74.67 & A53 & 72.350 & 0.0311 & Nov-11 & 87.88 & A73 & 97.075 & 0.1046 \\
\hline Jun-07 & 70.56 & A47 & 74.150 & 0.0509 & Dec-11 & 87.43 & A73 & 92.888 & 0.0624 \\
\hline Jul-07 & 61.87 & A37 & 70.738 & 0.1433 & Jan-12 & 97.81 & A85 & 92.888 & 0.0503 \\
\hline Aug-07 & 64.9 & $\mathrm{~A} 40$ & 63.000 & 0.0293 & Feb-12 & 108.9 & A94 & 101.606 & 0.0670 \\
\hline Sep-07 & 66.46 & A42 & 64.200 & 0.0340 & Mar-12 & 106.95 & A92 & 97.075 & 0.0923 \\
\hline Oct-07 & 71.72 & A49 & 71.800 & 0.0011 & Apr-12 & 105.54 & A91 & 105.200 & 0.0032 \\
\hline Nov-07 & 76.22 & A56 & 73.163 & 0.0401 & May-12 & 101.48 & A88 & 108.650 & 0.0707 \\
\hline Dec-07 & 74.58 & A53 & 77.275 & 0.0361 & Jun-12 & 88.44 & A74 & 88.450 & 0.0001 \\
\hline Jan-08 & 78.35 & A59 & 74.150 & 0.0536 & Jul-12 & 86.43 & A71 & 86.350 & 0.0009 \\
\hline Feb-08 & 81.93 & A65 & 82.150 & 0.0027 & Aug-12 & 76.17 & A56 & 76.300 & 0.0017 \\
\hline Mar-08 & 79.84 & A62 & 87.283 & 0.0932 & Sep-12 & 79.9 & A62 & 77.275 & 0.0329 \\
\hline Apr-08 & 81.88 & A65 & 84.017 & 0.0261 & Oct-12 & 84.15 & A68 & 84.017 & 0.0016 \\
\hline May-08 & 90.31 & A77 & 87.283 & 0.0335 & Nov-12 & 76.84 & A57 & 76.900 & 0.0008 \\
\hline Jun-08 & 98.45 & A85 & 93.938 & 0.0458 & Dec-12 & 80.29 & A62 & 74.283 & 0.0748 \\
\hline Jul-08 & 99.43 & A86 & 101.606 & 0.0219 & Jan-13 & 85.37 & A70 & 84.017 & 0.0159 \\
\hline Aug-08 & 90.37 & A77 & 100.275 & 0.1096 & Feb-13 & 82.8 & A66 & 82.850 & 0.0006 \\
\hline Sep-08 & 90.09 & A76 & 93.938 & 0.0427 & Mar-13 & 76.7 & A57 & 76.900 & 0.0026 \\
\hline Oct-08 & 58.13 & A32 & 58.250 & 0.0021 & Apr-13 & 72.03 & A49 & 74.283 & 0.0313 \\
\hline Nov-08 & 50.97 & $\mathrm{~A} 22$ & 50.800 & 0.0033 & May-13 & 80.52 & A63 & 73.163 & 0.0914 \\
\hline Dec-08 & 34.51 & $\mathrm{~A} 2$ & 46.850 & 0.3576 & Jun-13 & 77.16 & A57 & 76.900 & 0.0034 \\
\hline Jan-09 & 44.69 & A15 & 44.600 & 0.0020 & Jul-13 & 71.05 & A48 & 74.283 & 0.0455 \\
\hline Feb-09 & 44.93 & A15 & 44.600 & 0.0073 & Aug-13 & 70.53 & A47 & 70.200 & 0.0047 \\
\hline Mar-09 & 44.49 & A15 & 44.600 & 0.0025 & Sep-13 & 75.92 & A55 & 70.738 & 0.0683 \\
\hline Apr-09 & 49.56 & $\mathrm{~A} 21$ & 48.550 & 0.0204 & Oct-13 & 72.16 & A49 & 71.800 & 0.0050 \\
\hline May-09 & 52.74 & A24 & 46.850 & 0.1117 & Nov-13 & 70.38 & A47 & 73.163 & 0.0395 \\
\hline Jun-09 & 50.55 & A22 & 56.500 & 0.1177 & Dec-13 & 71.95 & A49 & 70.738 & 0.0169 \\
\hline Jul-09 & 52.27 & A24 & 46.850 & 0.1037 & Jan-14 & 65.75 & A41 & 73.163 & 0.1127 \\
\hline Aug-09 & 61.88 & A37 & 56.500 & 0.0869 & Feb-14 & 60.69 & A35 & 67.750 & 0.1163 \\
\hline Sep-09 & 65.29 & A41 & 63.000 & 0.0351 & Mar-14 & 64.81 & $\mathrm{~A} 40$ & 61.075 & 0.0576 \\
\hline Oct-09 & 69.66 & A46 & 67.750 & 0.0274 & Apr-14 & 61.9 & A37 & 64.200 & 0.0372 \\
\hline Nov-09 & 75.15 & A54 & 75.100 & 0.0007 & May-14 & 59.19 & A33 & 63.000 & 0.0644 \\
\hline Dec-09 & 81.97 & A65 & 82.150 & 0.0022 & Jun-14 & 60.94 & A35 & 60.600 & 0.0056 \\
\hline Jan-10 & 91.29 & A78 & 87.283 & 0.0439 & Jul-14 & 57.36 & A31 & 61.075 & 0.0648 \\
\hline Feb-10 & 94.15 & A82 & 94.650 & 0.0053 & Aug-14 & 52.01 & A23 & 51.700 & 0.0060 \\
\hline Mar-10 & 99.44 & A86 & 99.200 & 0.0024 & Sep-14 & 46.67 & $\mathrm{~A} 17$ & 46.300 & 0.0079 \\
\hline Apr-10 & 110.01 & A95 & 100.275 & 0.0885 & Oct-14 & 46.05 & $\mathrm{~A} 17$ & 46.300 & 0.0054 \\
\hline May-10 & 103.77 & A90 & 104.000 & 0.0022 & Nov-14 & 46.66 & $\mathrm{~A} 17$ & 46.300 & 0.0077 \\
\hline Jun-10 & 107.91 & A93 & 107.600 & 0.0029 & Dec-14 & 44.3 & A15 & 44.600 & 0.0068 \\
\hline Jul-10 & 98.04 & A85 & 98.025 & 0.0002 & Jan-15 & 46.94 & A18 & 48.550 & 0.0343 \\
\hline Aug-10 & 97.63 & A85 & 101.606 & 0.0407 & Feb-15 & 49.64 & A21 & 51.975 & 0.0470 \\
\hline Sep-10 & 100.85 & A87 & 101.606 & 0.0075 & Mar-15 & 48.28 & A19 & 46.850 & 0.0296 \\
\hline Oct-10 & 104.81 & A91 & 105.200 & 0.0037 & Apr-15 & 47.42 & A18 & 47.200 & 0.0046 \\
\hline Nov-10 & 116.58 & A98 & 108.650 & 0.0680 & May-15 & 53.79 & A26 & 51.975 & 0.0337 \\
\hline Dec-10 & 129.42 & A102 & 131.250 & 0.0141 & Jun-15 & 55.3 & A28 & 55.450 & 0.0027 \\
\hline Jan-11 & 152.59 & A106 & 151.750 & 0.0055 & Jul-15 & 49.24 & A20 & 49.000 & 0.0049 \\
\hline Feb-11 & 172.62 & A108 & 168.000 & 0.0268 & Aug-15 & 45.45 & A16 & 45.425 & 0.0006 \\
\hline Mar-11 & 140.12 & A104 & 140.500 & 0.0027 & Sep-15 & 41.59 & A11 & 41.400 & 0.0046 \\
\hline Apr-11 & 155.79 & A107 & 147.500 & 0.0532 & Oct-15 & 39.64 & A9 & 39.800 & 0.0040 \\
\hline May-11 & 140.39 & A104 & 140.500 & 0.0008 & Nov-15 & 36.49 & A5 & 36.600 & 0.0030 \\
\hline Jun-11 & 135.89 & A103 & 147.500 & 0.0854 & Dec-15 & 36.8 & A5 & 36.600 & 0.0054 \\
\hline
\end{tabular}




\section{CONCLUSION AND DISCUSSION}

The proposed method is suitable for Thailand rubber pricedata in sense of its accuracy. However, the traditional method is convenient method by using conventional package programing such as SPSS, SAS and MINITAB.For the time series data used for high precision forecasting, the proposed method is shown to be a good alternative because it produces high accuracy forecasting corresponding to the actual value.

\section{ACKNOWLEDGEMENT}

This study was supported by Dhurakij Pundit research service centerof Dhurakij Pundit university.

\section{REFERENCES}

[1] P. Grzegorzewski and E. Mrówka, "Trapezoidal approximations of fuzzy numbers," Fuzzy Sets and Systems, vol. 153, no. 1, pp. 115-135, 2005.

[2] P. Grzegorzewski and E. Mrówka, "Trapezoidal approximations of fuzzy numbers-revisited," Fuzzy Sets and Systems, vol. 158, no. 7, pp. 757-768, 2007. DOI: $10.1016 /$ j.fss.2006.11.015

[3] S. Rajaram and V. Vamitha, "A modified approach on fuzzy time series forecasting," Annals of Pure and Applied Mathematics, vol. 2, no. 1, pp. 96-106, 2012.
[4] Z. Horvath and R. Johnston, "AR (1) time series process econometrics 7590," 2016. [Online]. Available: http://goo.gl/FRhSvR [Accessed: 26 July, 2016].

[5] B. L. Bowerman, A. B. Koehler and R. T. O 'Connell, Forecasting Time Series and Regression, 4th ed., Belmont, CA: Phoenix Color Corp, 2005.

[6] G. A. Miller, "The magical number seven plus or minus two: Some limits on our capacity of processing information," The Psychological Review, vol. 63, no. 2, pp. 81- 97, 1956. DOI: 10.1037/h0043158

[7] Q. Song and B. Chissom, "Fuzzy forecasting enrollments with fuzzy time series Part 1," Fuzzy Sets and Systems, vol. 54, pp. 1-9, 1993. DOI: 10.1016/01650114(93)90355-L

[8] Q. Song and B. Chissom, "Fuzzy time series and it models," Fuzzy Sets and Systems, vol. 54, pp. 269-277, 1993. DOI: 10.1016/0165-0114(93)90372-0

[9] Q. Song and B. Chissom, "Forecasting enrollments with fuzzy time series Part 2," Fuzzy Sets and Systems, vol. 62, pp. 1-8, 1994. DOI:10.1016/0165-0114(94)90067 1

[10] "Rubber authority of Thailand," 2016. [Online]. Available: http://goo.gl/f86v9p [Accessed: 26 July, 2016].

— This article does not have any appendix. - 